\title{
Effect of ZnO Nanoparticle Content on the Structural and Ionic Transport Parameters of Polyvinyl Alcohol Based Proton-Conducting Polymer Electrolyte Membranes
}

\author{
Omed Gh. Abdullah ${ }^{1, *} \mathbb{1}$, Yahya A. K. Salman ${ }^{2}$, Dana A. Tahir ${ }^{3}$, Gelas M. Jamal ${ }^{1}$, Hawzhin T. Ahmed ${ }^{4}(\mathbb{D}$, \\ Azhin H. Mohamad ${ }^{5}$ and Auday K. Azawy ${ }^{3}$ \\ 1 Advanced Materials Research Laboratory, Department of Physics, College of Science, University of Sulaimani, \\ Kurdistan Region 46001, Iraq; gelas.jamal@univsul.edu.iq \\ 2 Department of Physics, College of Science, University of Mosul, Mosul 41002, Iraq; kareem200138@yahoo.com \\ 3 Department of Physics, College of Science, University of Halabja, Kurdistan Region 46006, Iraq; \\ dana.tahir@uoh.edu.iq (D.A.T.); auday@mail.ru (A.K.A.) \\ 4 Charmo Center for Research, Training and Consultancy, Charmo University, Kurdistan Region 46023, Iraq; \\ hawzhin.taha@charmouniversity.org \\ 5 Department of Physics, College of Education, University of Sulaimani, Kurdistan Region 46001, Iraq; \\ azhin.mohamad@univsul.edu.iq \\ * Correspondence: omed.abdullah@univsul.edu.iq
}

Citation: Abdullah, O.G..; Salman, Y.A.K.; Tahir, D.A.; Jamal, G.M.; Ahmed, H.T.; Mohamad, A.H.; Azawy, A.K. Effect of $\mathrm{ZnO}$ Nanoparticle Content on the Structural and Ionic Transport Parameters of Polyvinyl Alcohol Based Proton-Conducting Polymer Electrolyte Membranes. Membranes 2021, 11, 163. https://doi.org/ $10.3390 /$ membranes11030163

Academic Editor: Patric Jannasch

Received: 8 February 2021

Accepted: 22 February 2021

Published: 26 February 2021

Publisher's Note: MDPI stays neutral with regard to jurisdictional claims in published maps and institutional affiliations.

Copyright: (c) 2021 by the authors. Licensee MDPI, Basel, Switzerland. This article is an open access article distributed under the terms and conditions of the Creative Commons Attribution (CC BY) license (https:/ / creativecommons.org/licenses/by/ $4.0 /)$.

\begin{abstract}
Proton conducting nanocomposite solid polymer electrolytes (NSPEs) based on polyvinyl alcohol/ammonium nitrate (PVA/ $\mathrm{NH}_{4} \mathrm{NO}_{3}$ ) and different contents of zinc oxide nanoparticles ( $\mathrm{ZnO}$ NPs) have been prepared using the casting solution method. The XRD analysis revealed that the sample with $2 \mathrm{wt}$ \% ZnO-NPs has a high amorphous content. The ionic conductivity analysis for the prepared membranes has been carried out over a wide range of frequencies at varying temperatures. Impedance analysis shows that sample with $2 \mathrm{wt} . \% \mathrm{ZnO}-\mathrm{NPs}$ has a smaller bulk resistance compared to that of undoped polymer electrolyte. A small amount of ZnO-NPs was found to enhance the proton-conduction significantly; the highest obtainable room-temperature ionic conductivity was $4.71 \times 10^{-4} \mathrm{~S} / \mathrm{cm}$. The effect of $\mathrm{ZnO}-\mathrm{NP}$ content on the transport parameters of the prepared protonconducting NSPEs was investigated using the Rice-Roth model; the results reveal that the increase in ionic conductivity is due to an increment in the number of proton ions and their mobility.
\end{abstract}

Keywords: ZnO-NPs; proton-conducting; impedance; conductivity; transport parameters

\section{Introduction}

Research on proton-conducting solid polymer electrolytes (SPEs) over the past few decades has aimed to provide high-performance and stable electrochemical devices, such as electrochemical double-layer capacitors, light-emitting electrochemical cells, solid-state batteries, and fuel cells [1-3]. The proton transport in SPEs can be designated based on three mechanisms: hopping, diffusion, and transport associated with polymer chain segmental movement [4]. The ion hopping mechanism and ion transport by segmental motions are more favored at higher temperatures [5]. To investigate the proton conduction mechanism of a system, the ionic conductivity is typically characterized in terms of temperature [6].

Nonetheless, the greatest drawback of proton-conducting SPEs is their low ionic conductivity at room temperature, which restricts their practical applications in energy storage devices [7]. In recent years, significant efforts have been dedicated to enhancing ionic conduction in proton-conducting SPEs by different approaches, including polymer blending, copolymerization, the addition of plasticizers, and the incorporation of nanosized inorganic fillers to the system such as carbon nanotubes, reduced graphene oxide, and metal oxide. Among these approaches, the dispersion of a small amount of inorganic nano-sized fillers into the polymer electrolyte matrix has captured escalating interest 
by many researchers due to their high efficiency in improving the room-temperature ionic conductivity of an electrolyte system $[8,9]$. The overall impact of presenting nanosized inorganic fillers in SPEs depends on several factors, such as the type, shape, size, and concentration of nano-filler, as well the way in which the fillers are distributed and dispersed in the matrix [10,11].

Polyvinyl alcohol (PVA) has been extensively used as the host for electrolyte systems due to its hydrophilic properties, non-toxicity, water-solubility, biocompatibility, biodegradability, low cost, and good film-forming properties $[12,13]$. The hydroxyl $(\mathrm{O}-\mathrm{H})$ groups of PVA help in the dissociation of salts at high concentrations to form an ionic medium as a result of hydrogen bonding, which makes the PVA matrix a potential candidate in electronics and optoelectronics applications $[14,15]$.

Due to the polar nature of PVA, the ions of dissociated salt coordinate with polar groups of PVA backbone and form a charge-transfer complex, which causes the change in the structural, morphological, thermal, and electrical properties of PVA [3]. Thus, the physical and chemical properties of PVA can be tuned by the addition of salts [16]. Many researchers attempted to enhance the ionic conductivity of SPEs by incorporating different micro- or nano-sized inorganic fillers into the matrix to reduce the crystalline phase of the host polymer [17]. The suppression of crystallization in a semi-crystalline polymer host leads to enhancement in the segmental chain motion, consequently prompting better ionic conduction [18].

Zinc oxide nanoparticles (ZnO-NPs) are wide-bandgap semiconductors that possess optoelectrical characteristics. ZnO-NPs have been dispersed into several SPE systems to improve the ionic conductivity, structure and mechanical properties of the produced nanocomposite solid polymer electrolytes (NSPEs) [19]. Zebardastan et al. [20] investigated the properties of NSPEs, which consisted of different weight percentages of $\mathrm{ZnO}$ nano-filler in the PVdF-HFP:PEO:EC:PC:NaI: $\mathrm{I}_{2}: \mathrm{ZnO}$ system. The highest value of ionic conductivity was recorded when $3 \mathrm{wt} . \%$ of $\mathrm{ZnO}$ nanofiller was added into the system. They ascribed the enhancement in ionic conductivity to the increase in the amorphous portion in the system. Recently, Selvi et al. [21] studied the effect of ZnO-NP content on the optical, electrical, mechanical, and thermal properties of pure PVA. The results of the study revealed that the mechanical and thermal properties of PVA were improved upon adding ZnO-NPs.

Based on our recent published works [22,23], the proton-conducting SPE based on PVA loaded with $30 \mathrm{wt} . \%$ of $\mathrm{NH}_{4} \mathrm{NO}_{3}$ exhibits a maximum ionic conductivity of $5.17 \times 10^{-5} \mathrm{~S} / \mathrm{cm}$ at ambient temperature. Although the ionic conductivity of this SPE is enhanced, it is still insufficient for practical applications. In the present work, different contents of ZnO-NPs were dispersed in the proton-conducting PVA $/ \mathrm{NH}_{4} \mathrm{NO}_{3}$ polymer electrolyte membranes to produce NSPEs with enhanced ionic conductivity. The samples were prepared by a common casting technique, and their properties with different $\mathrm{ZnO}$ NP contents were compared. The prepared samples were characterized by impedance spectroscopy, where the data were analyzed as a function of composition, frequency, and temperature.

\section{Experimental}

\subsection{Sample Preparation}

Series films of proton-conducting PVA $/ \mathrm{NH}_{4} \mathrm{NO}_{3} / \mathrm{ZnO}$ NSPEs with different $\mathrm{ZnO}$ $\mathrm{NP}$ contents were prepared by the casting method. Referring to our previous works, the SPE based on PVA incorporated with $30 \mathrm{wt} . \% \mathrm{NH}_{4} \mathrm{NO}_{3}$ exhibited the highest roomtemperature ionic conductivity $[22,23]$. In this study, the SPE solution was prepared by dissolving $2 \mathrm{~g}$ of PVA in $40 \mathrm{~mL}$ of double-distilled water and heating for $60 \mathrm{~min}$ at $90{ }^{\circ} \mathrm{C}$. The PVA solution was cool at ambient temperature, and then $30 \mathrm{wt} . \% \mathrm{NH}_{4} \mathrm{NO}_{3}$ $(0.857 \mathrm{~g})$ dissolved separately in $5 \mathrm{~mL}$ was added to the viscous polymer solution, with continuous stirring for a further $45 \mathrm{~min}$ to ensure the intimate mixing. Later, different weight percentages of $\mathrm{ZnO}-\mathrm{NPs}$ ( 1 to $5 \mathrm{wt} . \%$ ) with particle sizes of $10-70 \mathrm{~nm}$ were added to the previous solution, and the mixtures were sonicated for $30 \mathrm{~min}$ to achieve homogeneous 
dispersion of NPs. The homogeneous solutions were then poured into various clean Petri dishes and left to dry in the air under ambient conditions for a two-week period for the membranes to form. After air-drying, the samples were stored in a desiccator with silica gel to ensure that the films were completely dried prior to subsequent experimentation and characterizations. The nanocomposite solid polymer electrolyte (NSPE) membranes were coded as NSPE-0, NSPE-1, NSPE-2, NSPE-3, NSPE-4, and NSPE-5, for a proton-conducting PVA $/ \mathrm{NH}_{4} \mathrm{NO}_{3}$ polymer electrolyte, loaded with $0,1,2,3,4$, and $5 \mathrm{wt} . \%$ of $\mathrm{ZnO}-\mathrm{NPs}$, respectively. The scheme for sample preparation is depicted in Figure 1.

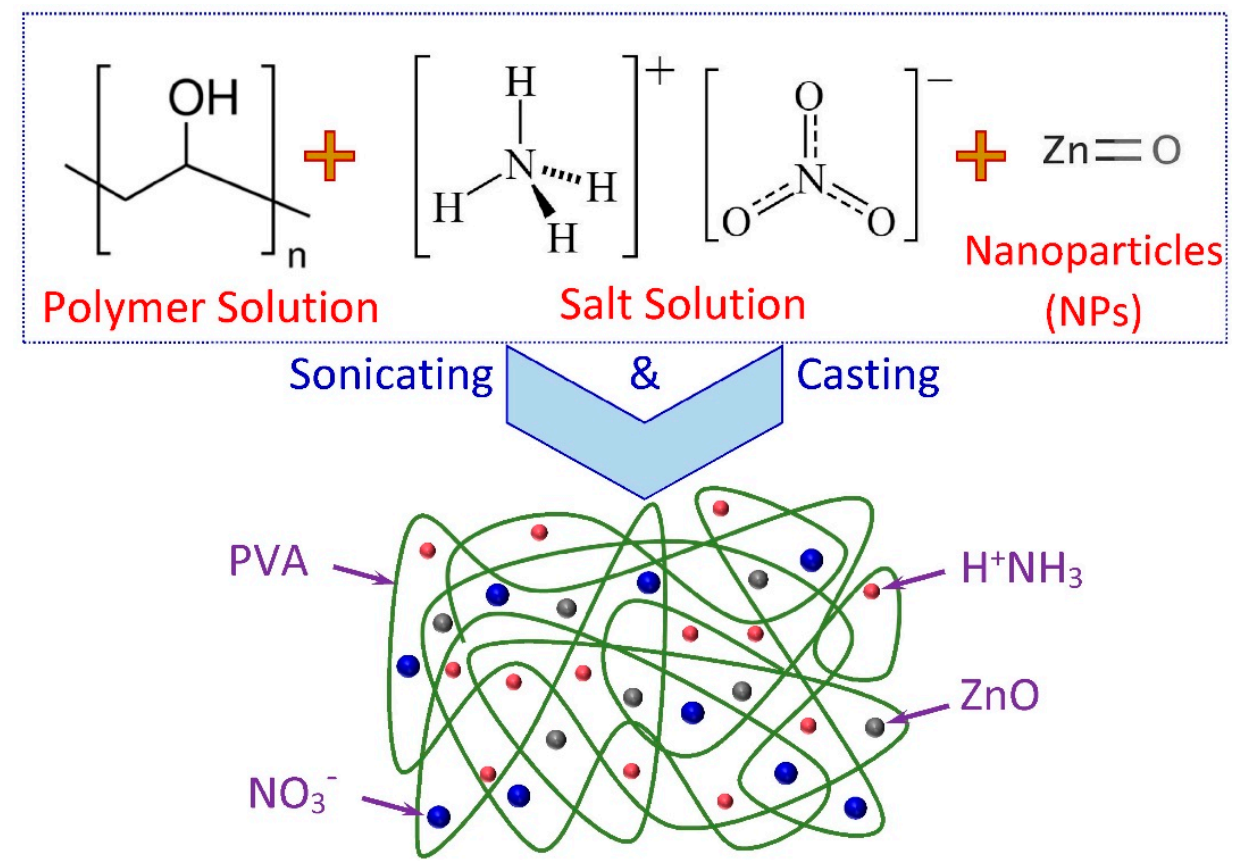

Figure 1. Sample preparation and characterization scheme for proton-conducting polyvinyl alcohol (PVA) $/ \mathrm{NH}_{4} \mathrm{NO}_{3} / \mathrm{ZnO}$ nanocomposite solid polymer electrolytes (NSPEs).

\subsection{Characterizations}

The X-ray diffraction (XRD) pattern of the prepared proton-conducting PVA/ $\mathrm{NH}_{4} \mathrm{NO}_{3} /$ ZnO NSPEs was collected using a Bruker D8 diffractometer (Karlsruhe, Germany), with Cu-K $\alpha$ radiation $=1.5418 \AA$, in the $2 \theta$ range between $10^{\circ}$ and $70^{\circ}$. The instrument operated at $40 \mathrm{kV}$ and $40 \mathrm{~mA}$.

The surface morphology of the prepared samples was conducted by scanning electron microscopy (SEM, JEOL JSM-6060) (Tokyo, Japan), operating at $20 \mathrm{kV}$. The samples were sputtered with thin gold layers prior to imaging.

Electrochemical impedance spectroscopy (EIS) measurements were performed in the frequency range from $100 \mathrm{~Hz}$ to $2 \mathrm{MHz}$ and in the temperature range $303 \mathrm{~K}$ to $353 \mathrm{~K}$ to examine the effect of $\mathrm{ZnO}-\mathrm{NPs}$ on the ionic conductivity of proton-conducting PVA $/ \mathrm{NH}_{4} \mathrm{NO}_{3}$ polymer electrolytes. The impedance was measured with a KEYSIGHT E4980A LCR Meter (Santa Rosa, CA, USA) that has been interfaced with a computer. The proton-conducting NSPE samples were mounted on the holder with aluminum blocking electrodes of diameter $1 \mathrm{~cm}$ under spring pressure to ensure good contact between NSPE films and electrodes. In this study, the semicircular arc of the Cole-Cole plot of complex impedance was used to obtain the bulk resistance $\left(R_{b}\right)$, and the electrical conductivity $(\sigma)$ of the samples was calculated from this equation:

$$
\sigma=\frac{l}{R_{b} A}
$$


Here, $l$ and $A$ are, respectively, the sample thickness and the area of the electrode. A micrometer gauge was used to determine the thickness of films and was found to range from 240 to $315 \mu \mathrm{m}$.

\section{Results and Discussion}

\subsection{XRD Analysis}

The XRD patterns for PVA $/ \mathrm{NH}_{4} \mathrm{NO}_{3} / \mathrm{ZnO}$ NSPEs with varying $\mathrm{ZnO}-\mathrm{NP}$ contents are shown in Figure 2. The XRD patterns for all samples exhibit a broad peak centered at $2 \theta=19.25^{\circ}$, corresponding to the semi-crystalline nature of PVA that arises from the intra- and inter-molecular hydrogen bonding of the $\mathrm{O}-\mathrm{H}$ groups in the PVA backbone [24]. However, the presence of $\mathrm{NH}_{4} \mathrm{NO}_{3}$ crystalline peaks in all samples at $18.07^{\circ}, 22.61^{\circ}, 24.46^{\circ}$, $29.10^{\circ}, 36.24^{\circ}$, and $40.38^{\circ}$ indicates the presence of some undissociated $\mathrm{NH}_{4} \mathrm{NO}_{3}$ salt in the NSPE samples [25].

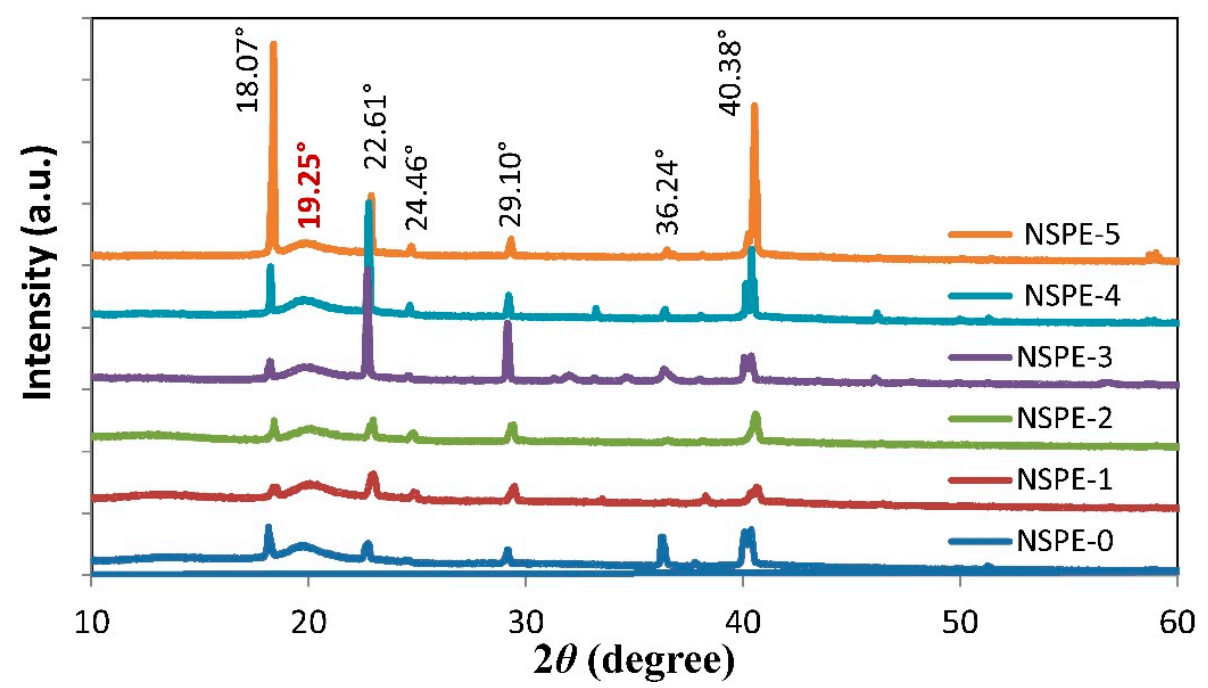

Figure 2. XRD pattern plots for PVA $/ \mathrm{NH}_{4} \mathrm{NO}_{3} / \mathrm{ZnO}$ NSPEs with different $\mathrm{ZnO}$-nanoparticle (NP) contents.

The minimum intensity of the characteristic peaks upon loading $2 \mathrm{wt}$ \% $\mathrm{ZnO}-\mathrm{NP}$ reveals the lowest relative crystallinity of the NSPE-2 sample. Beyond this concentration, the intensity of the $\mathrm{NH}_{4} \mathrm{NO}_{3}$ peaks increases as the $\mathrm{ZnO}-\mathrm{NP}$ concentration increases, which causes a decrement in the conductivity due to the recombination of the dissociated ions to form $\mathrm{NH}_{4} \mathrm{NO}_{3}$ salt. It has been well reported that even a small change in the crystallinity of polymer samples has a profound effect on the conductivity [26-28].

\subsection{SEM Study}

Figure 3 depicts the scanning electron microscope (SEM) micrographs of $\mathrm{PVA} / \mathrm{NH}_{4} \mathrm{NO}_{3} /$ $\mathrm{ZnO}$ NSPEs with different ZnO-NP contents. It can be seen that the morphology of undoped and doped proton-conducting polymer electrolytes consists of solid structures that have protruded out of the membrane surface, revealing that the $\mathrm{NH}_{4} \mathrm{NO}_{3}$ salt has recrystallized out of the NSPE surface, which is in good agreement with the XRD results. It is also clear that the density of the solid structures reduced after the addition of $2 \mathrm{wt} . \%$ of ZnO-NPs. A further increase in $\mathrm{ZnO}-\mathrm{NP}$ content resulted in a further increase in the size and density of these solid structures in the polymer electrolytes. This observation is in agreement with the aforementioned XRD analysis.

\subsection{Impedance Analysis}

Figure 4 represents the Cole-Cole plots of complex impedance for samples with $0,1,2$, 3,4 , and $5 \mathrm{wt}$ \% $\mathrm{ZnO}-\mathrm{NPs}$ loaded PVA $/ \mathrm{NH}_{4} \mathrm{NO}_{3}$ polymer electrolytes at room temperature. 
The profile plots show a part of a depressed semicircle for all samples. The semicircle arc symbolizes the parallel combination of bulk resistance (due to mobile ions inside the polymer matrix) and bulk capacitance (due to immobile polymer chains) [29]. As the $\mathrm{ZnO}$ content increases, the semicircle in the plots was observed to lessen up to $2 \mathrm{wt} . \%$; beyond this concentration, the trend is reversed.
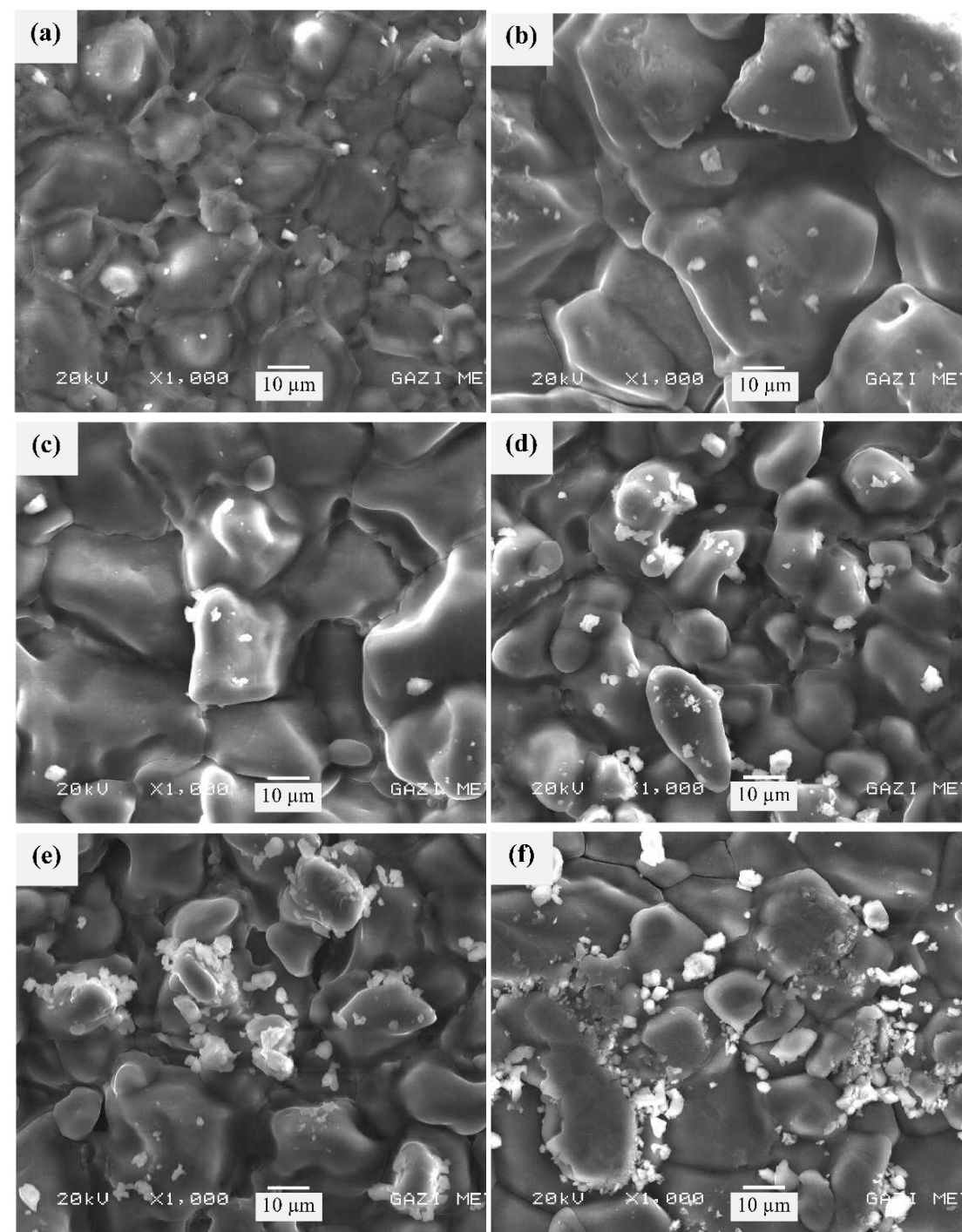

Figure 3. Scanning electron microscope (SEM) micrographs of $\mathrm{PVA} / \mathrm{NH}_{4} \mathrm{NO}_{3} / \mathrm{ZnO}$ NSPEs with different ZnO-NP concentrations: (a) NSPE-0, (b) NSPE-1, (c) NSPE-2, (d) NSPE-3, (e) NSPE-4, and (f) NSPE-5.

The $R_{b}$ for NSPE samples has been found from the intercept of the semicircle arc at low-frequency on the real $Z^{\prime}$ axis. As shown in the inset of Figure 4 , the $R_{b}$ has been found to be $6.92 \times 10^{6}, 7.36 \times 10^{5}, 1.79 \times 10^{5}, 7.51 \times 10^{5}, 5.64 \times 10^{6}$, and $1.15 \times 10^{7} \Omega$ for $0,1,2$, 3,4 , and $5 \mathrm{wt} . \%$ content of $\mathrm{ZnO}-\mathrm{NPs}$, respectively.

The conductivity of proton-conducting PVA $/ \mathrm{NH}_{4} \mathrm{NO}_{3} / \mathrm{ZnO}$ NSPE membranes was observed to increase with temperature. At high temperatures, the dissociation of ammonium nitrate and the thermal movement of PVA molecular chain segments would be improved, which caused an increase in the ionic conductivity.

The complex-plane impedance plots of the NSPE-2 sample at different temperatures are presented in Figure 5. It is obvious that, as the temperature increased, the depressed semicircular arc in the plots was observed to lessen and finally disappear, leaving only a low-frequency spike. This suggests the existence of only the resistive component $[29,30]$, 
which reveals the absence of capacitive nature; therefore, only the diffusion processes take place at high temperatures [31].
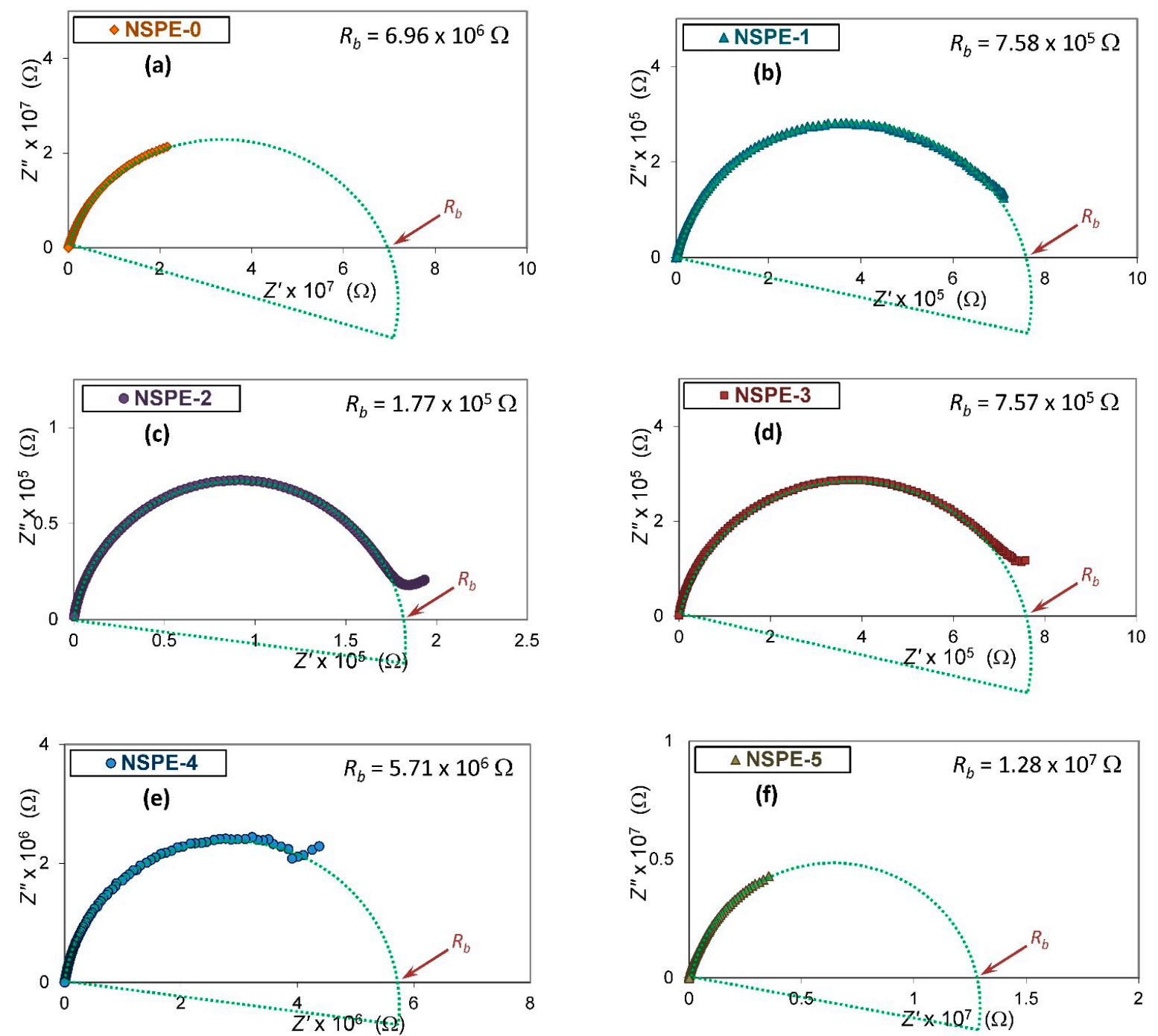

Figure 4. Impedance plots of $\mathrm{PVA} / \mathrm{NH}_{4} \mathrm{NO}_{3}$ polymer electrolyte samples containing 0 wt.\% (a); 1 wt. \% (b); 2 wt.\% (c); 3 wt.\% (d); 4 wt.\% (e); and 5 wt.\% (f) of $\mathrm{ZnO}-\mathrm{NPs}$ at room temperature.

\subsection{Conductivity Analysis}

The variation in room-temperature direct current $(\mathrm{DC})$ conductivity $\left(\sigma_{D C}\right)$ versus $\mathrm{ZnO}-\mathrm{NP}$ content is presented in Figure 6. The dependence of $\sigma_{D C}$ on $\mathrm{ZnO}$ content provides information on the particular interaction between ions of $\mathrm{NH}_{4} \mathrm{NO}_{3}$ salt and the functional group of the PVA matrix. Kadir et al. [32] reported that the chitosan-PVA- $\mathrm{NH}_{4} \mathrm{NO}_{3}$ proton-conducting system gives the optimum value of ionic conductivity $2.07 \times 10^{-5} \mathrm{~S} / \mathrm{cm}$ at room temperature upon incorporating $40 \mathrm{wt} . \%$ salt, which is comparable with the undoped SPE sample in the present work. The peak observed in Figure 6 depicts the roomtemperature highest DC conductivity optimized at $4.71 \times 10^{-4} \mathrm{~S} / \mathrm{cm}$ with the addition of $2 \mathrm{wt} . \%$ of ZnO-NPs. Beyond that, the ionic conductivity decreases quickly. Tripathi and Kumar [33] attributed the decrease in conductivity with increasing $\mathrm{ZnO}$ concentration beyond $3 \mathrm{wt} . \%$ in plasticized polymer gel electrolytes based on poly(vinylidene fluoride)co-hexafluoropropylene (PVDF-HFP) to the small value of $\mathrm{ZnO}-\mathrm{NPs}^{\prime}$ dielectric constant compared to the polymer gel electrolyte system. 

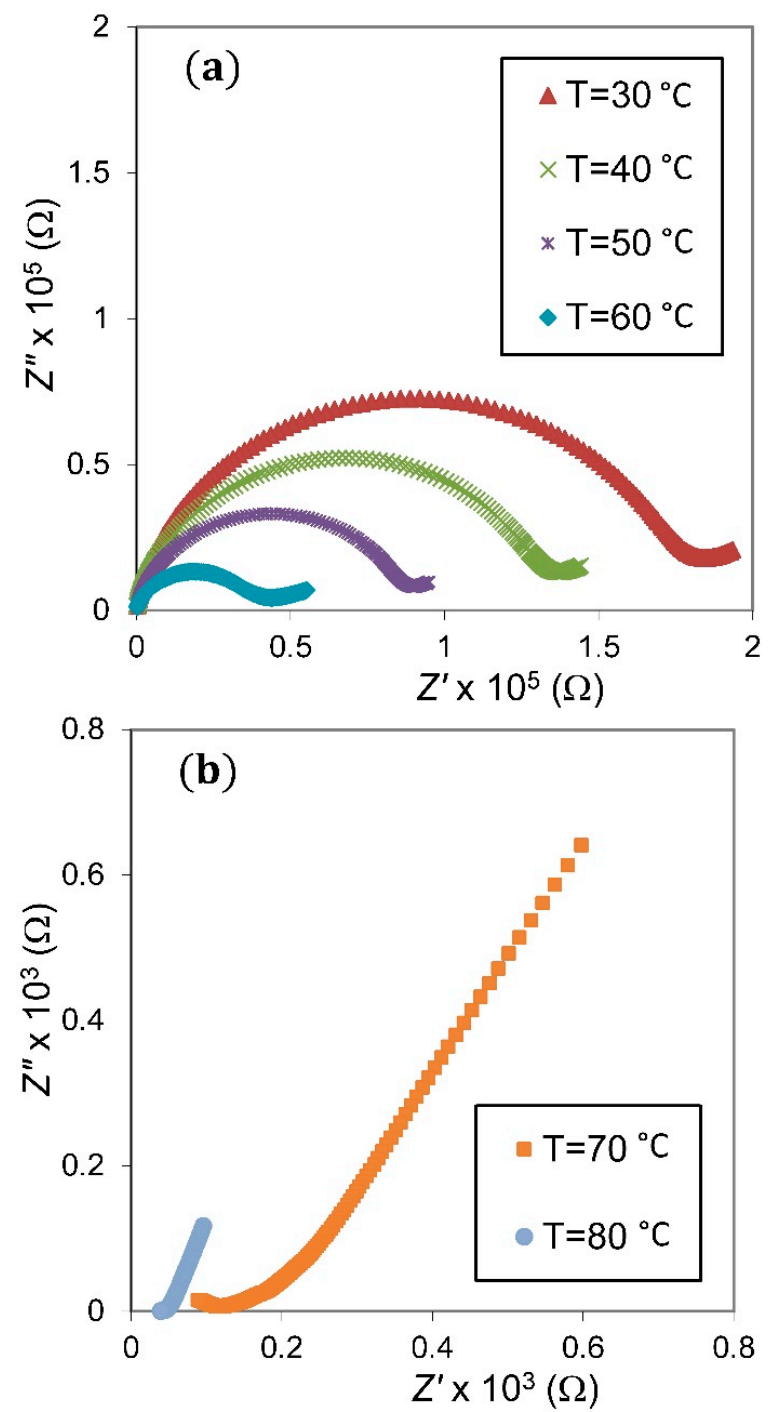

Figure 5. Impedance plot of the NSPE-2 sample at temperatures of $30-60^{\circ} \mathrm{C}(\mathbf{a})$ and $70-80{ }^{\circ} \mathrm{C}(\mathbf{b})$.

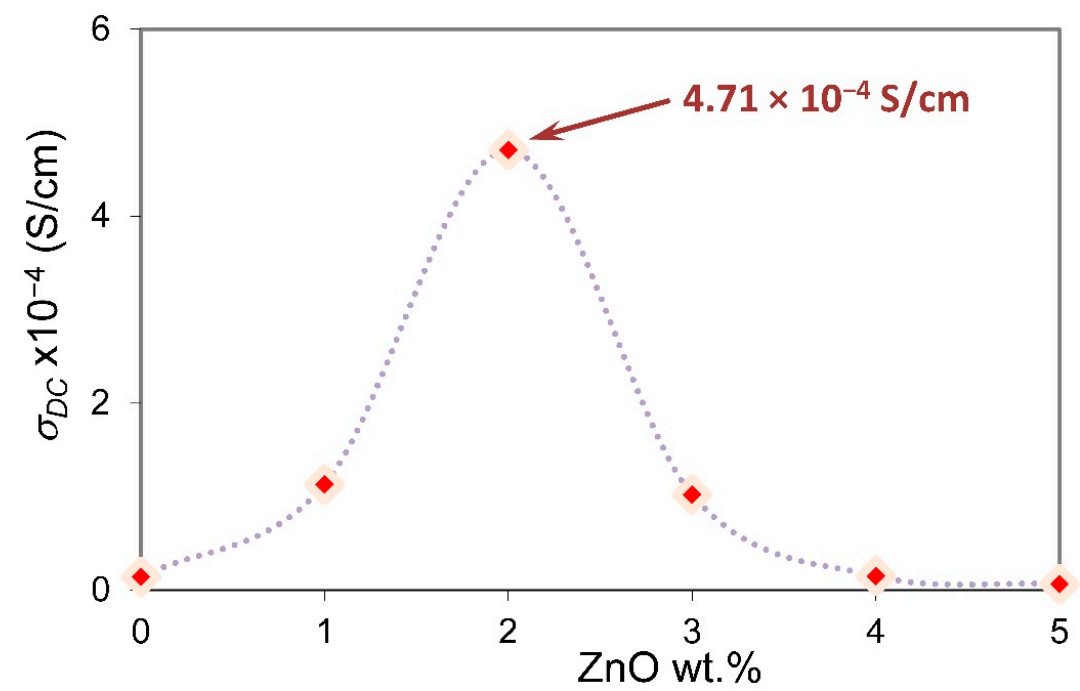

Figure 6. Ionic conductivity as a function of $\mathrm{ZnO} w \mathrm{w} . \%$ at room temperature. 
The average value of $\sigma_{D C}$ for all prepared samples is tabulated in Table 1 . The increases in $\sigma_{D C}$ with the addition of $\mathrm{ZnO}$-NPs could be related to the increase in both the number and mobility of free carriers in the matrix by increasing the degree of salt dissociation of ion aggregates, and increasing the amorphous phase content, respectively $[34,35]$.

Table 1. Transport parameters for PVA/ $\mathrm{NH}_{4} \mathrm{NO}_{3} / \mathrm{ZnO}$ nanocomposite solid polymer electrolytes (NSPEs) samples at room temperature.

\begin{tabular}{|c|c|c|c|c|c|c|}
\hline Samples & $\begin{array}{c}\sigma_{D C} \times 10^{-4} \\
\left(\mathrm{~S} \mathrm{~cm}^{-1}\right)\end{array}$ & $\begin{array}{c}E_{A} \\
(\mathrm{eV})\end{array}$ & $\begin{array}{c}\tau \times 10^{-14} \\
(\mathrm{~s})\end{array}$ & $\begin{array}{c}n \times 10^{18} \\
\left(\mathrm{~cm}^{3}\right)\end{array}$ & $\begin{array}{c}\mu \times 10^{-4} \\
\left(\mathrm{~cm}^{2} V^{-1} \mathrm{~s}\right)\end{array}$ & $\begin{array}{l}D \times 10^{-8} \\
\left(\mathrm{~cm}^{2} \mathrm{~s}^{-1}\right)\end{array}$ \\
\hline NSPE-1 & 1.133 & 0.912 & 3.64 & 4.71 & 1.50 & 3.93 \\
\hline NSPE-2 & 4.710 & 0.906 & 3.65 & 18.8 & 1.57 & 4.10 \\
\hline NSPE-3 & 1.021 & 0.914 & 3.63 & 4.28 & 1.49 & 3.90 \\
\hline NSPE-4 & 0.152 & 0.920 & 3.62 & 0.67 & 1.42 & 3.71 \\
\hline NSPE-5 & 0.067 & 0.925 & 3.61 & 0.31 & 1.38 & 3.60 \\
\hline
\end{tabular}

The temperature-dependence of ionic conductivity has been employed to analyze the possible ion-conduction mechanism in the present proton-conducting NSPEs. Figure 7 shows the plot of $\log \sigma_{D C}$ versus $1000 / T$ for different $\mathrm{ZnO}-\mathrm{NP}$ contents in PVA $/ \mathrm{NH}_{4} \mathrm{NO}_{3}$ polymer electrolyte membranes. The linear variation of these plots suggests that the thermally activated process exhibits the Arrhenius-type behavior [36]. However, the observed linear relations for all doped $\mathrm{PVA} / \mathrm{NH}_{4} \mathrm{NO}_{3}$ polymer electrolyte samples mean that there is no phase transition marked in the NSPEs by adding ZnO-NPs. As per this model, the temperature-dependent $\sigma_{D C}$ can be expressed by activation energy $\left(E_{A}\right)$, which is obtained in terms of the Arrhenius equation [37]:

$$
\sigma_{D C}=\sigma_{o} \exp \left(\frac{-E_{A}}{k_{B} T}\right)
$$

where $\sigma_{o}$ and $k_{B}$ represent the pre-exponential factor and Boltzmann constant, respectively. The value of $E_{A}$ was calculated using the grade of the Arrhenius plot shown in Figure 7.

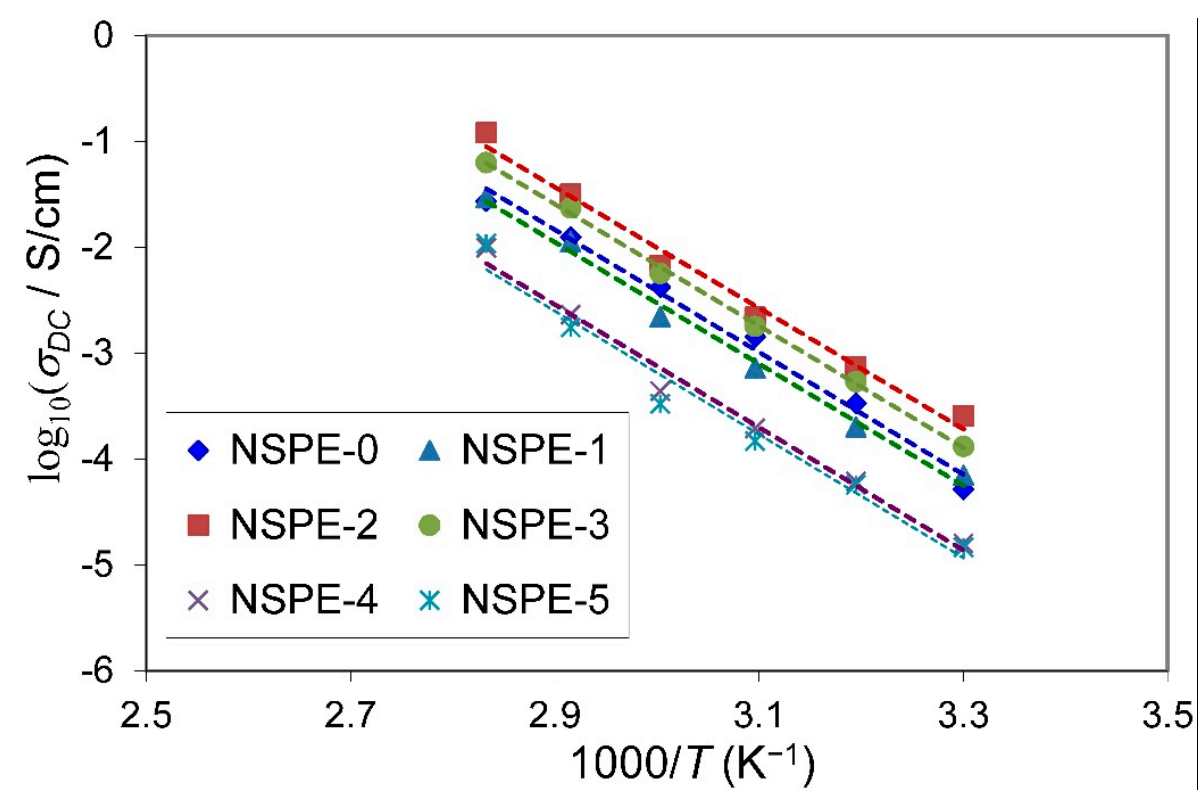

Figure 7. Temperature-dependent direct current (DC) conductivity for PVA/ $\mathrm{NH}_{4} \mathrm{NO}_{3} / \mathrm{ZnO}$ NSPEs.

The increase in the $\sigma_{D C}$ of NSPEs with temperature can be understood as the hopping of proton ions between PVA coordinating sites; hopping being helped by both polymer chain segmental motions and local structural relaxations [38]. As the temperature increases, the amorphous domains gradually increase, and the polymer chains earn faster internal 
modes producing segmental motion due to bond rotations. As a result, ion hopping due to inter- and intra-chain movements is favored, causing the spectacular to enhance the conductivity of the matrix $[39,40]$. The calculated values of $\sigma_{D C}$ and $E_{A}$ in accordance with $\mathrm{ZnO}$ content are presented in Table 1 , which also shows that the $E_{A}$ is inversely proportional to the $\sigma_{D C}$ in the manner that the highest conductivity sample (NSPE-2) shows the minimum value of hopping activation energy. Here, the $E_{A}$ has been assigned as the energy acquired by the $\mathrm{H}^{+}$ion to free itself from its localized-state. This reveals that incorporating a small amount (2 wt.\%) of $\mathrm{ZnO}-\mathrm{NPs}$ into the PVA $/ \mathrm{NH}_{4} \mathrm{NO}_{3}$ polymer electrolyte causes a reduction in the potential energy barriers for the proton transport, leading to a decrease in the activation energy [41]. This result is expected and comparable with much previous work for different proton-conducting polymer electrolyte systems [29,34,42]. Hema et al. [43] also observed that the temperature-dependent conductivity for the proton-conducting polymer electrolyte based on PVA- $\mathrm{NH}_{4} \mathrm{Cl}, \mathrm{PVA}-\mathrm{NH}_{4} \mathrm{Br}$, and $\mathrm{PVA}-\mathrm{NH}_{4} \mathrm{I}$ followed the Arrhenius-type relationship.

\subsection{Dielectric Study}

The dielectric study of the present proton-conducting NSPEs was carried out to understand the conductivity behavior of the systems and is explained in terms of the real $\left(M^{\prime}\right)$ and imaginary $\left(M^{\prime \prime}\right)$ parts of electric modulus, as they are free from the contribution of the interfacial electrode/electrolyte polarization effect at low frequencies. The dielectric study gives information on relaxing dipoles in the samples [44]. The obtained complex permittivity $\left(\varepsilon^{*}\right)$ data were analyzed using complex modulus $\left(M^{*}\right)$, which is an inverse of the $\varepsilon^{*}$ and is linked to the impedance data as follows:

$$
M^{*}=\frac{1}{\varepsilon^{*}}=j \omega C_{o} Z^{*}
$$

Here, $\omega$ is the angular frequency ( $\omega=2 \pi f, f$ being frequency), $C_{o}=\varepsilon_{0} A / d$, where $\varepsilon_{o}$ is the free space permittivity, $A$ is the cross-section of the electrode, and $d$ is the film thickness, and $Z^{*}$ is the complex impedance.

The variations of real $\left(M^{\prime}\right)$ and imaginary $\left(M^{\prime \prime}\right)$ parts of electric modulus for the PVA $/ \mathrm{NH}_{4} \mathrm{NO}_{3}$ doped 2 wt.\% $\mathrm{ZnO}$ at various temperatures are introduced in Figure 8. The plot of $M^{\prime}$ and $M^{\prime \prime}$ shows low value at lower frequencies, which is caused by the huge value of interfacial capacitance correlated with the electrode-electrolyte boundary [34]. However, no definitive peaks can be observed for the $M^{\prime}$ plot, and the $M^{\prime \prime}$ spectrum shows an asymmetry relaxation peak accompanied by the dispersion of $M^{\prime}$ in the frequency range employed in this study. The broadness and asymmetry shape of the $M^{\prime \prime}$ peak disclose the distribution of relaxation time and non-Debye relaxation process [14,45].

A shift in the $M^{\prime \prime}$ relaxation peak towards the higher-frequency side with a temperature rise indicates the reduction in the relaxation time, which directly supports the ionic conductivity enhancement as a consequence of an increase in the mobility of free ions [17]. According to Khiar and Arof [46], as temperature increases, the degree of salt dissociation and re-dissociation of ion aggregates causes an increase in the number of free ions.

The combined plots of $Z^{\prime \prime}$ and $M^{\prime \prime}$ against frequency are usually used to identify whether the short-range or long-range motion of free carriers is dominant in the relaxation process. The mismatch of frequency peaks between $Z^{\prime \prime}$ and $M^{\prime \prime}$ reflects that the shortrange movement of free carriers is the predominant process and departs from the ideal Debye-type model, whereas the coincidence of the frequency peaks at a similar frequency implies that the long-range movement of free carriers is dominant [47]. The frequency response of normalized $Z^{\prime \prime} / Z^{\prime \prime}$ max and $M^{\prime \prime} / M^{\prime \prime}$ max for the sample with 2 wt.\% of ZnO-NPs at temperatures 30 and $60^{\circ} \mathrm{C}$ was represented in Figure 9. From this figure, it is noticed that the $Z^{\prime \prime} / Z^{\prime \prime}$ max and $M^{\prime \prime} / M^{\prime \prime}$ max peaks do not concur, indicating the short-range movement of free carriers and non-Debye relaxation processes in the present proton-conducting NSPE sample. The mismatch between the $Z^{\prime \prime} / Z^{\prime \prime}$ max and $M^{\prime \prime} / M^{\prime \prime}$ max peaks become larger with increasing temperature, which suggests the increases in the portion of the short-range 
movement of free carriers with increasing temperature. This result is in accordance with previous works, which suggest that the conductivity increases with increasing temperature.
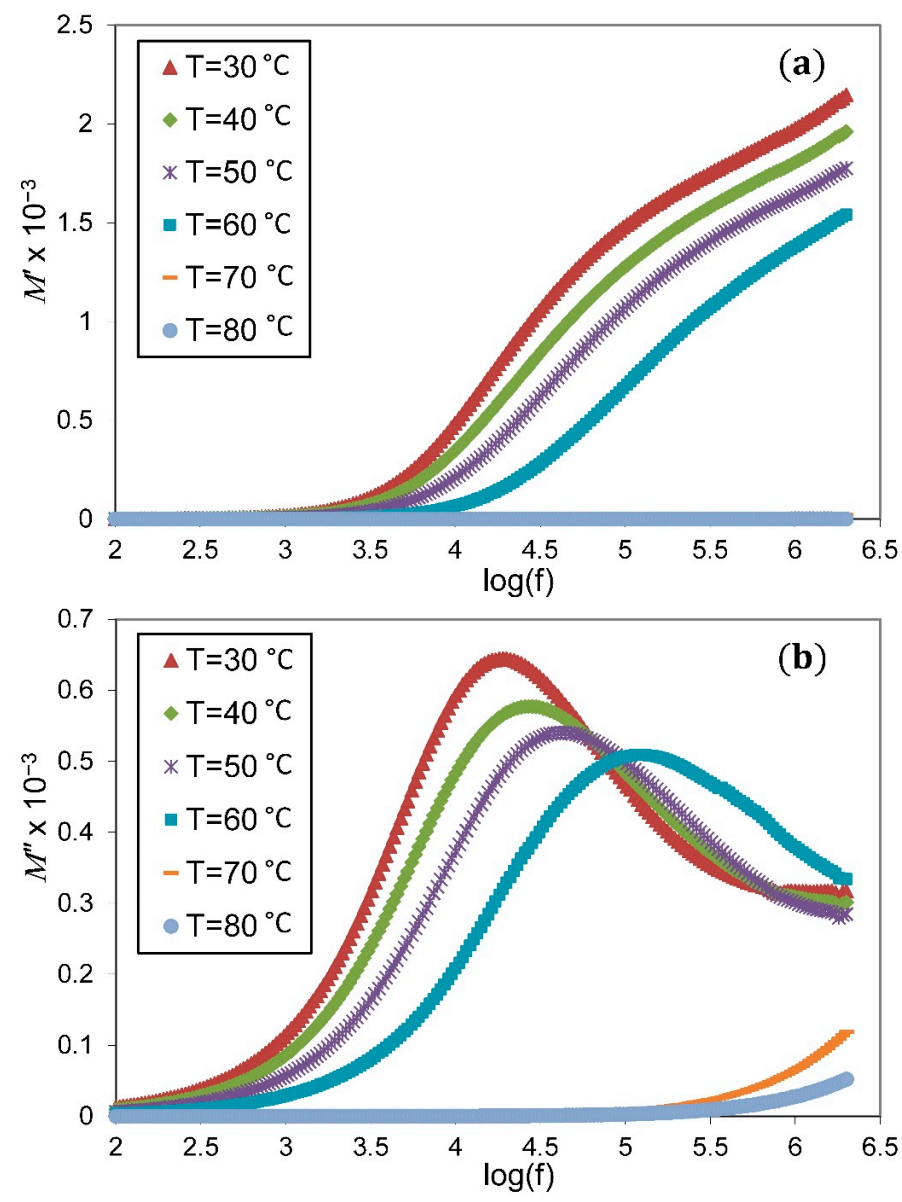

Figure 8. Plot of $(\mathbf{a})$ real $\left(M^{\prime}\right)$ and $(\mathbf{b})$ imaginary $\left(M^{\prime \prime}\right)$ parts of electric modulus versus frequency for the PVA/ $\mathrm{NH}_{4} \mathrm{NO}_{3}$ doped $2 \mathrm{wt} \% \mathrm{ZnO}$ at various temperatures.

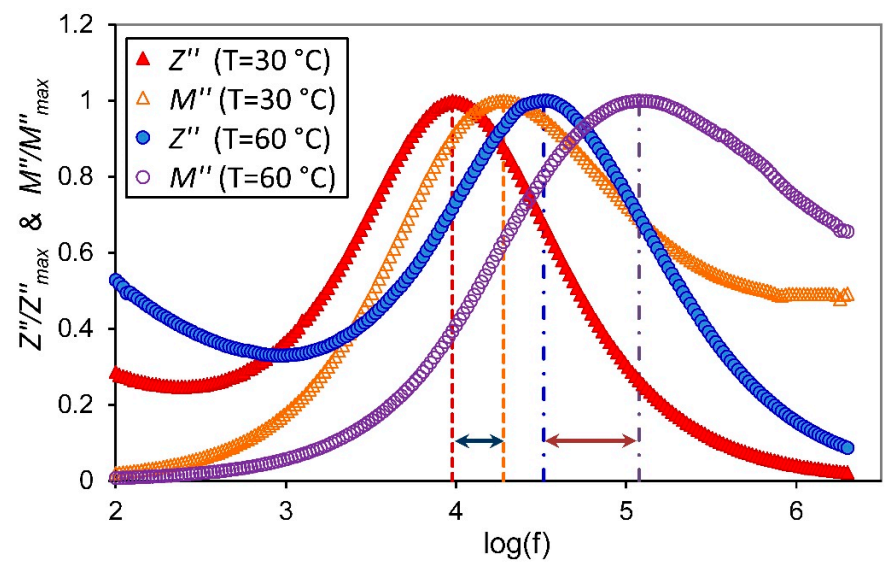

Figure 9. The change of normalized imaginary parts of impedance $\left(Z^{\prime \prime} / Z^{\prime \prime}\right.$ max $)$ and electric modulus $\left(M^{\prime \prime} / M^{\prime \prime}\right.$ max $)$ versus frequency at temperatures of $30^{\circ} \mathrm{C}$ and $60^{\circ} \mathrm{C}$ for the PVA $/ \mathrm{NH}_{4} \mathrm{NO}_{3}$ doped 2 wt.\% ZnO-NPs.

\subsection{Ion Transport Parameters}

Ion transport parameters such as charge carrier density $(n)$, its mobility $(\mu)$, and the diffusion coefficient $(D)$ of the present proton-conducting PVA $/ \mathrm{NH}_{4} \mathrm{NO}_{3} / \mathrm{ZnO} \mathrm{NSPE}$ 
membranes are investigated in detail using the Rice-Roth model [48]. This model postulated that the ionic carrier of mass $m$ in the localized states could be thermally excited to a free-ion-like state after receiving energy equal to the activation energy of conduction $\left(E_{A}\right)$; wherein the ion is propagated through the electrolyte with a velocity (v) [49], given by: $v=\sqrt{2 E_{A} / m}$. The mean free path of ion transport or the distance traveled by the ion between two complexation sites $(\uparrow)$ is given as: $\ell=v \tau$, where $\tau$ is the time of ions' travel from one complex site to another. In the present work, $\ell$ is the hopping distance between two repeating units of hydroxyl groups in PVA, which is taken to be around $2.15 \AA[50,51]$.

According to the Rice-Roth model, the ionic conductivity of free mobile ion is expressed as:

$$
\sigma=\frac{1}{3}\left[\frac{(Z e)^{2}}{k_{B} T}\right] n \ell v \exp \left(-\frac{E_{A}}{k_{B} T}\right)
$$

Here, $Z$ is the valency of the conducting ions, $e$ is the electron charge, and $k_{B}$ is the Boltzmann constant. Equation (4) was used to evaluate the number density of mobile ions ( $n$ ). From the estimated value of $n$, the ionic mobility $(\mu=\sigma / n e)$ and diffusion coefficient $\left(D=k_{B} T \sigma / n e^{2}\right)$ of the samples can also be calculated. Table 1 shows the value of $n, \mu$, and $D$ for the PVA $/ \mathrm{NH}_{4} \mathrm{NO}_{3} / \mathrm{ZnO}$ NSPEs samples with different $\mathrm{ZnO}$ contents. It is seen from the table that the maximum conducting sample has a maximum value of $n$ and $\mu$, which confirms that the conductivity in the present NSPEs is actually controlled by both the number and mobility of $\mathrm{H}^{+}$ions in the samples. These studies indicate that the conductivity of the PVA/ $\mathrm{NH}_{4} \mathrm{NO}_{3}$ polymer electrolyte can be enhanced moderately by adding a small percentage of $\mathrm{ZnO}-\mathrm{NPs}$, owing to the increase in both the mobility and number density of mobile proton ions.

\section{Conclusions}

Proton-conducting PVA/ $\mathrm{NH}_{4} \mathrm{NO}_{3} / \mathrm{ZnO}$ NSPE membranes with different contents of $\mathrm{ZnO}-\mathrm{NPs}$ were prepared using the cast technique. The small percentage of ZnO-NPs was found to influence the proton-conduction of the system, and the highest obtained value of conductivity is $4.71 \times 10^{-4} \mathrm{~S} / \mathrm{cm}$ at room temperature. The temperature-dependent ionic conductivity results exhibited Arrhenius behavior, and the activation energy values were inversely proportional to the DC conductivity. Dielectric studies suggest that the NSPE samples in this study exhibit non-Debye behavior, and the relaxation process is caused by the short-range movement of free carriers. The application of the Rice-Roth model deduced that the increase in conductivity arose from the increase in the mobility and number density of mobile proton ions in the system.

Author Contributions: Conceptualization, O.G.A.; methodology, H.T.A. and A.H.M.; formal analysis, O.G.A., Y.A.K.S., and G.M.J.; resources, D.A.T. and A.K.A.; data curation, O.G.A., and D.A.T.; writing-original draft preparation, O.G.A., H.T.A. and A.H.M.; writing-review and editing, All authors have read and agreed to the published version of the manuscript.

Funding: This research received no external funding.

Institutional Review Board Statement: The study was conducted according to the guidelines of the Declaration of Helsinki, and approved by the Ethics Committee of University of Sulaimani.

Informed Consent Statement: Not applicable.

Data Availability Statement: The authors confirm that the data supporting the findings of this study are available within the article.

Acknowledgments: All authors would like to express their gratefulness to the staff members of the Advanced Materials Research Laboratory at the Physics Department, the University of Sulaimani, for providing the facilitates for this work.

Conflicts of Interest: The authors declare no conflict of interest. 


\section{References}

1. Gao, H.; Lian, K. Proton-conducting polymer electrolytes and their applications in solid supercapacitors: A review. RSC Adv. 2014, 4, 33091. [CrossRef]

2. Long, Z.; Miyake, J.; Miyatake, K. Sulfonated poly(arylene perfluoroalkylene) terpolymers as novel proton exchange membranes for high performance fuel cells. Bull. Chem. Soc. Jpn. 2020, 93, 338-344. [CrossRef]

3. Hegde, S.; Ravindrachary, V.; Praveena, S.D.; Guruswamy, B.; Sagar, R.N. Microstructural, dielectric, and transport properties of proton-conducting solid polymer electrolyte for battery applications. Ionics 2020, 26, 2379-2394. [CrossRef]

4. Son, C.Y.; Wang, Z.G. Ion transport in small-molecule and polymer electrolytes. J. Chem. Phys. 2020, 153, 100903. [CrossRef]

5. Patra, S.; Puthirath, A.B.; Vineesh, T.V.; Narayanaru, S.; Soman, B.; Suriyakumar, S.; Stephan, A.M.; Narayanan, T.N. On the development of a proton conducting solid polymer electrolyte using poly(ethylene oxide). Sustain. Energy Fuels 2018, 2, 1870-1877. [CrossRef]

6. Sohaimy, M.I.H.; Isa, M.I.N. Ionic conductivity and conduction mechanism studies on cellulose based solid polymer electrolytes doped with ammonium carbonate. Polym. Bull. 2017, 74, 1371-1386. [CrossRef]

7. Regu, T.; Ambika, C.; Karuppasamy, K.; Jeon, J.H.; Jeong, Y.T.; Vikraman, D.; Raj, T.A.B.; Kim, H.S. $\mathrm{Al}_{2} \mathrm{O}_{3}$-incorporated proton-conducting solid polymer electrolytes for electrochemical devices: A proficient method to achieve high electrochemical performance. Ionics 2019, 25, 5117-5129. [CrossRef]

8. Boaretto, N.; Meabe, L.; Martinez-Ibanez, M.; Armand, M.; Zhang, H. Review-Polymer electrolytes for rechargeable batteries: From nanocomposite to nanohybrid. J. Electrochem. Soc. 2020, 167, 070524. [CrossRef]

9. Choudhary, S.; Sengwa, R.J. Effects of different inorganic nanoparticles on the structural, dielectric and ion transportation properties of polymers blend based nanocomposite solid polymer electrolytes. Electrochim. Acta 2017, 247, 924-941. [CrossRef]

10. Mohamad, A.H.; Saeed, S.R.; Abdullah, O.G. Synthesis of very-fine PbS nanoparticles dispersed homogeneously in MC matrix: Effect of concentration on the structural and optical properties of the host polymer. Mater. Res. Express 2019, 6, 115332. [CrossRef]

11. Bdewi, S.F.; Abdullah, O.G.; Aziz, B.K.; Mutar, A.A.R. Synthesis, structural and optical characterization of MgO nanocrystalline embedded in PVA matrix. J. Inorg. Organomet. Polym. Mater. 2016, 26, 326-334. [CrossRef]

12. Pandi, D.V.; Selvasekarapandian, S.; Bhuvaneswari, R.; Premalatha, M.; Monisha, S.; Arunkumar, D.; Junichi, K. Development and characterization of proton conducting polymer electrolyte based on PVA, amino acid glycine and NH $\mathrm{NCN}_{4}$. Solid State Ion. 2016, 298, 15-22. [CrossRef]

13. Abdullah, O.G.; Aziz, S.B.; Rasheed, M.A. Structural and optical characterization of PVA:KMnO 4 based solid polymer electrolyte. Results Phys. 2016, 6, 1103-1108. [CrossRef]

14. Abdelrazek, E.M.; Abdelghany, A.M.; Tarabiah, A.E.; Zidan, H.M. AC conductivity and dielectric characteristics of PVA/PVP nanocomposite filled with MWCNTs. J. Mater. Sci. Mater. Electron. 2019, 30, 15521-15533. [CrossRef]

15. Abdullah, O.G.; Tahir, D.A.; Kadir, K. Optical and structural investigation of synthesized PVA/PbS nanocomposites. J. Mater. Sci. Mater. Electron. 2015, 26, 6939-6944. [CrossRef]

16. Taghizadeh, M.T.; Sabouri, N. Biodegradation behaviors and water adsorption of poly(vinyl alcohol)/starch/carboxymethyl cellulose/clay nanocomposites. Int. Nano Lett. 2013, 3, 51. [CrossRef]

17. Arya, A.; Sadiq, M.; Sharma, A.L. Effect of variation of different nanofillers on structural, electrical, dielectric, and transport properties of blend polymer nanocomposites. Ionics 2018, 24, 2295-2319. [CrossRef]

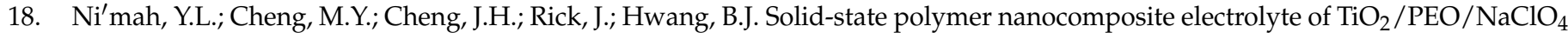
for sodium ion batteries. J. Power Sources 2015, 278, 375-381. [CrossRef]

19. Xiong, H.M.; Zhao, X.; Chen, J.S. New polymer-inorganic nanocomposites: PEO-ZnO and PEO-ZnO-LiClO 4 films. J. Phys. Chem. B 2001, 105, 10169-10174. [CrossRef]

20. Zebardastan, N.; Khanmirzaei, M.H.; Ramesh, S.; Ramesh, K. Performance enhancement of poly (vinylidene fluoride-cohexafluoro propylene)/polyethylene oxide based nanocomposite polymer electrolyte with ZnO nanofiller for dye-sensitized solar cell. Org. Electron. 2017, 49, 292-299. [CrossRef]

21. Selvi, J.; Parthasarathy, V.; Mahalakshmi, S.; Anbarasan, R.; Daramola, M.O.; Kumar, P.S. Optical, electrical, mechanical, and thermal properties and non-isothermal decomposition behavior of poly(vinyl alcohol)-ZnO nanocomposites. Iran. Polym. J. 2020, 29, 411-422. [CrossRef]

22. Saeed, M.A.M.; Abdullah, O.G. Effect of high ammonium salt concentration and temperature on the structure, morphology, and ionic conductivity of proton-conductor solid polymer electrolytes based PVA. Membranes 2020, 10, 262. [CrossRef]

23. Saeed, M.A.M.; Abdullah, O.G. Effect of structural features on ionic conductivity and dielectric response of PVA proton conductor based solid polymer electrolytes. J. Electron. Mater. 2021, 50, 432-442. [CrossRef]

24. Abdullah, O.G. Synthesis of single-phase zinc chromite nano-spinel embedded in polyvinyl alcohol films and its effects on energy band gap. J. Mater. Sci. Mater. Electron. 2016, 27, 12106-12111. [CrossRef]

25. Moniha, V.; Alagar, M.; Selvasekarapandian, S.; Sundaresan, B.; Boopathi, G. Conductive bio-polymer electrolyte iota-carrageenan with ammonium nitrate for application in electrochemical devices. J. Non-Cryst. Solids 2018, 481, 424-434. [CrossRef]

26. Ahmed, H.T.; Abdullah, O.G. Preparation and composition optimization of PEO:MC polymer blend films to enhance electrical conductivity. Polymers 2019, 11, 853. [CrossRef]

27. Yusof, Y.M.; Illias, H.A.; Shukur, M.F.; Kadir, M.F.Z. Characterization of starch-chitosan blend-based electrolyte doped with ammonium iodide for application in proton batteries. Ionics 2017, 23, 681-697. [CrossRef] 
28. Abdullah, O.G.; Hanna, R.R.; Salman, Y.A.K. Structural, optical, and electrical characterization of chitosan: Methylcellulose polymer blends based film. J. Mater. Sci. Mater. Electron. 2017, 28, 10283-10294. [CrossRef]

29. Ramya, C.S.; Selvasekarapandian, S.; Savitha, T.; Hirankumar, G.; Baskaran, R.; Bhuvaneswari, M.S.; Angelo, P.C. Conductivity and thermal behavior of proton conducting polymer electrolyte based on poly (N-vinyl pyrrolidone). Eur. Polym. J. 2006, 42, 2672-2677. [CrossRef]

30. Ahmed, H.T.; Abdullah, O.G. Structural and ionic conductivity characterization of PEO:MC-NH $\mathrm{I}_{4}$ proton-conducting polymer blend electrolytes based films. Results Phys. 2020, 16, 102861. [CrossRef]

31. Ibrahim, S.; Yassin, M.M.; Ahmad, R.; Johan, M.R. Effects of various $\mathrm{LiPF}_{6}$ salt concentrations on PEO-based solid polymer electrolytes. Ionics 2011, 17, 399-405. [CrossRef]

32. Kadir, M.F.Z.; Majid, S.R.; Arof, A.K. Plasticized chitosan-PVA blend polymer electrolyte based proton battery. Electrochim. Acta 2010, 55, 1475-1482. [CrossRef]

33. Tripathi, M.; Kuma, A. Zinc oxide nanofiller-based composite polymer gel electrolyte for application in EDLCs. Ionics 2018, 24, 3155-3165. [CrossRef]

34. Ahmed, H.T.; Abdullah, O.G. Impedance and ionic transport properties of proton-conducting electrolytes based on polyethylene oxide/methylcellulose blend polymers. J. Sci. Adv. Mater. Devices 2020, 5, 125-133. [CrossRef]

35. Mohamad, A.H.; Abdullah, O.G.; Saeed, S.R. Effect of very fine nanoparticle and temperature on the electric and dielectric properties of MC-PbS polymer nanocomposite films. Results Phys. 2020, 16, 102898. [CrossRef]

36. Abdullah, O.G.; Salman, Y.A.K.; Saleem, S.A. Electrical conductivity and dielectric characteristics of in situ prepared PVA/HgS nanocomposite films. J. Mater. Sci. Mater. Electron. 2016, 27, 3591-3598. [CrossRef]

37. Xie, X.-X.; Yang, Y.-C.; Dou, B.-H.; Li, Z.-F.; Li, G. Proton conductive carboxylate-based metal-organic frameworks. Coordin. Chem. Rev. 2020, 404, 213100. [CrossRef]

38. Abdullah, O.G.; Aziz, S.B.; Saber, D.R.; Abdullah, R.M.; Hanna, R.R.; Saeed, S.R. Characterization of polyvinyl alcohol film doped with sodium molybdate as solid polymer electrolytes. J. Mater. Sci. Mater. Electron. 2017, 28, 8928-8936. [CrossRef]

39. Baskaran, R.; Selvasekarapandian, S.; Hirankumar, G.; Bhuvaneswari, M.S. Dielectric and conductivity relaxations in PVAc based polymer electrolytes. Ionics 2004, 10, 129-134. [CrossRef]

40. Abdullah, O.G.; Hanna, R.R.; Salman, Y.A.K. Structural and electrical conductivity of CH:MC bio-poly-blend films: Optimize the perfect composition of the blend system. Bull. Mater. Sci. 2019, 42, 64. [CrossRef]

41. Aziz, S.B.; Abdullah, O.G.; Al-zangana, S. Solid polymer electrolytes based on chitosan: $\mathrm{NH}_{4} \mathrm{Tf}$ modified by various amounts of $\mathrm{TiO}_{2}$ filler and its electrical and dielectric characteristics. Int. J. Electrochem. Sci. 2019, 14, 1909-1925. [CrossRef]

42. Mohamed, A.S.; Shukur, M.F.; Kadir, M.F.Z.; Yusof, Y.M. Ion conduction in chitosan-starch blend based polymer electrolyte with ammonium thiocyanate as charge provider. J. Polym. Res. 2020, 27, 149. [CrossRef]

43. Hema, M.; Selvasekarapandian, S.; Arunkumar, D.; Sakunthala, A.; Nithya, H. FTIR, XRD and ac impedance spectroscopic study on PVA based polymer electrolyte doped with $\mathrm{NH}_{4} \mathrm{X}(\mathrm{X}=\mathrm{Cl}, \mathrm{Br}, \mathrm{I})$. J. Non-Cryst. Solids 2009, 355, 84-90. [CrossRef]

44. Abdullah, O.G.; Saleem, S.A. Effect of copper sulfide nanoparticles on the optical and electrical behavior of poly (vinyl alcohol) films. J. Electron. Mater. 2016, 45, 5910-5920. [CrossRef]

45. Ahmed, H.T.; Jalal, V.J.; Tahir, D.A.; Mohamad, A.H.; Abdullah, O.G. Effect of PEG as a plasticizer on the electrical and optical properties of polymer blend electrolyte $\mathrm{MC}-\mathrm{CH}-\mathrm{LiBF}_{4}$ based films. Results Phys. 2019, 15, 102735. [CrossRef]

46. Khiar, A.S.A.; Arof, A.K. Conductivity studies of starch-based polymer electrolytes. Ionics 2010, 16, 123-129. [CrossRef]

47. Tang, R.; Jiang, C.; Qian, W.; Jian, J.; Zhang, X.; Wang, H.; Yang, H. Dielectric relaxation, resonance and scaling behaviors in $\mathrm{Sr}_{3} \mathrm{Co}_{2} \mathrm{Fe}_{24} \mathrm{O}_{41}$ hexaferrite. Sci. Rep. 2015, 5, 13645. [CrossRef] [PubMed]

48. Rice, M.J.; Roth, W.L. Ionic transport in super ionic conductors: A theoretical model. J. Solid. State. Chem. 1972, 4, 294-310. [CrossRef]

49. Salman, Y.A.K.; Abdullah, O.G.; Hanna, R.R.; Aziz, S.B. Conductivity and electrical properties of chitosan-methylcellulose blend biopolymer electrolyte incorporated with lithium tetrafluoroborate. Int. J. Electrochem. Sci. 2018, 13, 3185-3199. [CrossRef]

50. Rathod, S.G.; Bhajantri, R.F.; Ravindrachary, V.; Pujari, P.K.; Nagaraja, G.K.; Naik, J.; Hebbar, V.; Chandrappa, H. Temperaturedependent ionic conductivity and transport properties of $\mathrm{LiClO}_{4}$-doped PVA/modified cellulose composites. Bull. Mater. Sci. 2015, 38, 1213-1221. [CrossRef]

51. Aziz, S.B.; Abdullah, O.G.; Rasheed, M.A. Structural and electrical characteristics of PVA:NaTf based solid polymer electrolytes: Role of lattice energy of salts on electrical DC conductivity. J. Mater. Sci. Mater. Electron. 2017, 28, 12873-12884. [CrossRef] 